\title{
Article
}

\section{Sustainable Financing of Innovative Therapies: A Review of Approaches}

\author{
Hollis, Aidan
}

Available at http://clok.uclan.ac.uk/14908/

Hollis, Aidan (2016) Sustainable Financing of Innovative Therapies: A Review of Approaches. PharmacoEconomics, 34 (10). pp. 971-980. ISSN 1170-7690

It is advisable to refer to the publisher's version if you intend to cite from the work. http://dx.doi.org/10.1007/s40273-016-0416-x

For more information about UCLan's research in this area go to http://www.uclan.ac.uk/researchgroups/ and search for <name of research Group>.

For information about Research generally at UCLan please go to http://www.uclan.ac.uk/research/

All outputs in CLoK are protected by Intellectual Property Rights law, including Copyright law. Copyright, IPR and Moral Rights for the works on this site are retained by the individual authors and/or other copyright owners. Terms and conditions for use of this material are defined in the policies page.

\section{CLoK}

Central Lancashire online Knowledge www.clok.uclan.ac.uk

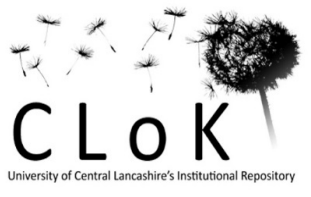




\title{
Sustainable Financing of Innovative Therapies: A Review of Approaches
}

\author{
Aidan Hollis \\ Department of Economics and O’Brien Institute for Public Health \\ University of Calgary \\ ahollis@ucalgary.ca
}

This is a pre-print version of an article in PharmacoEconomics. The final publication is available at Springer via http://dx.doi.org/10.1007/s40273-016-0416-x

\begin{abstract}
The process of innovation is inherently complex, and it occurs within an even more complex institutional environment characterized by incomplete information, market power, and externalities. There are therefore different competing approaches to supporting and financing innovation in medical technologies, which bring their own advantages and disadvantages. This article reviews value- and cost-based pricing, as well direct government funding, and cross-cutting institutional structures. It argues that performance-based risk-sharing agreements are likely to have little effect on the sustainability of financing; that there is a role for cost-based pricing models in some situations; and that the push towards longer exclusivity periods is likely contrary to the interests of industry.
\end{abstract}

\section{Introduction}

Financing of innovative therapies requires, ultimately, the allocation of resources large enough to support innovation, while sustainability requires that payers find that the innovation delivers good value, compared to other potential ways of allocating their resources. This review explores the literature on the different approaches taken by governments and insurers to balance these two conflicting goals.

The responses to these problems are of several types, but we can, for the most part, categorize them into three different broad strategies. The first response is "valuebased pricing", in which reimbursement or pricing depends on the therapeutic value of the product. The second response is "cost-based pricing", in which reimbursement or pricing is based on the imputed cost of the product. The third response is "direct 
funding" of innovation through government grants or product-development partnerships. In addition, there are other strategies that work within or across each of these three pricing strategies. I discuss each of these strategic responses in turn.

The set of actors that provide financing for innovation is large and varied. National governments and product-development partnerships may provide direct funding; insurers typically fund through the prices that they pay, but these may be influenced by the direct funding model employed. These actors typically have very different goals, with insurers focused on getting the best outcomes from the existing set of therapies, while government policy may have an additional focus of trying to encourage innovation. In many cases, governments are also interested in industrial development: research and manufacturing jobs in pharmaceuticals are politically attractive. These actors may also have differing ideas about what is valuable. Arguments commonly include about whose health to value; whether to include patient and caregiver convenience; how to weigh future health benefits; how to incorporate cost savings; and whether to reward technical inventiveness. These issues often underlie disputes about the value of innovation, but I abstract from them in this essay and assume a common understanding of what is valuable. As Pekarsky notes, in addition, innovation may arise in many domains, including clinical, resource-saving, and manufacturing.(1)

\section{Value-based pricing}

I use the term "value-based pricing" to indicate a pricing model according to which the reimbursed prices for innovative therapies are more or less related to the net incremental benefits delivered by therapies. For example, in an idealized model, the insurer would set the same reimbursement per incremental Quality-Adjusted LifeYear (QALY) generated by different novel therapies, but VBP can be influential even when it neither perfectly not universally implemented. Generally, the shift towards reliance on health technology assessments (HTA) has moved payers towards a VBP framework. The adoption of HTA processes in more and more countries is shown by the rapid growth of the International Network of Agencies for Health Technology Assessment.(2) While HTA has been a health policy instrument in many countries at least since the 1980s, in the last 15 years it has become to an increasing extent central to decisions on pricing and reimbursement.(3)

Paying for what society values seems like an obvious approach, but because it is technically challenging, insurers often use alternative approaches, such as setting prices based on prices in other countries or on prices of other comparable drugs. $(4,5)$ Similarly, manufacturers will seek prices that are not consistent with VBP on the basis that their drug is special: for example, because it treats a rare disease, or provides "end of life" care, or the like. $(6,7)$

In comparison to alternative approaches, VBP generally offers the promise of increased sustainability for two reasons. First, by targeting scarce resources at the most cost-effective technologies, it ensures that society gets better value for money. Second, the incentives of innovators are aligned with the interests of society under VBP. Thus 
VBP, broadly defined, is a central part of ensuring sustainable financing of innovative therapies.

VBP has attractive features, but there are many, many details that must be addressed.(8) First, exactly what dimensions of value are to included and measured? Value could incorporate not only health benefits - as summarized, for example, in QALYs - but also other dimensions, including patient convenience, cost savings, degree of innovation, and cost of R\&D. There is unfortunately no consensus about what dimensions of value should be taken into account.(9) In addition, there are arguments commonly made for special consideration of unmet needs or disease characteristics that are not included in the QALY. Measuring and aggregating the various dimensions of value, with adjustments, is then required. And then the payer must identify a threshold willingness to pay per unit of "value".

The problems of measurement of value are daunting, as suggested by the updated 2015 ISPOR guidelines on cost-effectiveness research.(10) One particularly challenging area is that generic instruments such as HUI-3 or EQ-5D, while effective for comparing across a wide range of health outcomes, are often alleged to be insufficiently sensitive to health outcomes within a particular disease. There has therefore been an efflorescence of disease-specific measurement instruments, although mapping to generic measures such as the QALY has introduced additional uncertainty.(11)(12)

In addition, pre-approval clinical trials may fail to reflect the value of the therapy in a real-world setting. The 2015 ISPOR guidelines therefore argue that it is "generally acknowledged that pragmatic effectiveness trials are the best vehicle for economic studies".(10) Pragmatic clinical trials, while they deliver information about the actual effectiveness of therapies in the population, are also costly and technically challenging. In addition, they may impose a heavy burden on healthcare systems to deliver reliable information, and create new ethical problems that must be addressed.(13)(14)

One of the central components of the VBP approach to funding new therapies is that it requires the funders to determine an appropriate threshold for costeffectiveness.(15) There are two general approaches to determining this threshold. In the "demand" side model, the threshold is based on societal willingness to pay. The insurer's budget must thus adjust to accommodate all treatments that meet the threshold. In the "supply" side model, the healthcare budget is set, and the threshold reflects the opportunity cost within the set of treatments available. In either case, an underlying principle in VBP is that the value obtained from expenditures on each intervention, at the margin, should be greater than the value that can be obtained from using the resources in any other way.(16) The implementation of th supply-side model requires setting a threshold based on opportunity cost. If the threshold is set too high, then the payers will end up harming health outcomes by funding new therapies that displace expenditures on other more cost-effective treatments. This result can easily arise, nonetheless, if payers lack comprehensive information about opportunity cost in their health system or have a bias in favor of identifiable patients over the unidentified patients whose treatment is displaced.(17) While the UK's National Health Service 
(NHS) has traditionally used a threshold in the range of $\AA^{20,000}$ to $£, 30,000$, Claxton et al have recently made an argument that the central mean marginal price of a QALY in the NHS is approximately $\mathcal{E}_{1} 12,900$.(18) This would imply that innovative therapies funded by the NHS at prices that were deemed acceptable because of incremental cost per QALY of, say, $£ 20,000$ will harm overall health outcomes. Pekarsky convincingly argues that the payer needs to consider what is being displaced, recognizing the political economy in which pharmaceutical companies have considerable sway over policy, while other competitively-provided therapy - such as nursing care - is less well represented by lobbyists.(1)

The threshold values used in high-income countries have been centered around a \$50,000 per QALY for many years.(9) However, the range of estimates for the most appropriate threshold is relatively wide. The World Health Organization has proposed that a interventions with a cost per QALY of 3 times GDP are costeffective, while interventions costing less than 1 times GDP are highly cost effective.(19)(20) This approach has attracted considerable criticism for its failure to reflect local circumstances.(20) Recent empirical work suggests that for many low- and middle-income countries, the relevant opportunity costs within the health system is much lower than the WHO-recommended threshold, and probably below per capita GDP.(21)(22)

A much lower cost-effectiveness threshold for new therapies will reduce the flow of investment into innovation, which in turn would imply that the "sustainable" flow of innovative therapies should be set at a relatively low level. If the threshold is set too high, it will support an "unsustainable" level of innovation in the sense that expenditures on the innovation deliver negative value to society.(1) If instead the threshold is set too low, the flow of innovation will be stifled and patients will not have access to cost-effective treatments.

\subsection{Expenditure caps}

Expenditure caps are an important strategy commonly used by payers in recent years as an addition to VBP. These are packaged in different ways: "risk-sharing agreements" and "managed entry agreements" in which the expenditures of the insurer on a given drug are capped at an agreed amount.(23) These kinds of agreements are often portrayed as offering risk-mitigation for the risk-averse insurer.(24) It is hard to understand what risks are mitigated, since the expenditure on a given drug is generally only a tiny fraction of total health care expenditures by the insurer. Nevertheless, many insurers require manufacturers to provide "budget impact assessments" whose main purpose appears to be to limit expenditure on those drugs anticipated to have a large total cost.(25)

An expenditure cap appears to work against the incentives created by VBP, since it limits the upside of the manufacturer and thus reduces the motivation to develop the therapies with the greatest potential to improve population health. Nevertheless, an expenditure cap may still be optimal to reduce investment in innovation. A well-known result in economics shows that racing to obtain a patent can induce excessive, duplicative effort.(26) This is similar to the insight that there 
may be excessive entry in industries with monopolistic competition. And indeed, we see in pharmaceutical markets that racing and duplication are common: "The prevailing drug development paradigm is one in which a number of firms will pursue investigational drugs with similar chemical structures or the same mechanism of action before any drug in the class obtains regulatory marketing approval."(27) The arrival of many direct-acting antivirals to treat hepatitis $C$ in the last few years is a classic example of this phenomenon.

Racing within a class is more probable when the class of drugs offers a large prize (i.e., patent-based exclusivity) to the early entrants. If the prize is reduced, the extent of duplication and racing will also be reduced. This can increase the overall efficiency of the industry, since fewer resources are expended in an effort to capture the same reward. Creating a revenue cap may be an efficient strategy to address this issue. However, this requires a complex balancing act: we want to create the incentives that will encourage firms to engage in exactly the most socially beneficial amount of research on the right projects. By reducing the prize for succeeding in the largest markets, we may have little effect on development speed of therapies in those classes, while leaving more resources available for research in other areas. In effect, there is an argument that the optimal allocation of resources should not be linearly related to the total therapeutic benefits achieved. (However, when a jurisdiction represents only a small fraction of the global demand for the product, it must have only a small impact on the process of drug development.)

One perspective on this is that this is exactly the strategy we observe for orphan drugs: they are, in effect, often allowed a high price on the basis that their revenues otherwise might be too small to justify investment in research and development.(7) Of course, this requires that the insurer balance the benefits from more rapid development of high-value therapies against the benefits from development of more therapies that have a relatively small effect on population health.

\subsection{Approval conditions}

Another method to reduce inefficiency created by excessive competition is to make the approval conditions for "me-too" or "follow-on" drugs more restrictive than for "first in class" drugs.(28) Payers can effectively achieve the same outcome by requiring large discounts from later entrants as a condition for obtaining formulary listing or favorable insurance status. Discouraging later entrants helps to reduce competitive promotional spending, and could thus increase the profitability of industry. Again, we see this kind of approach being used for orphan drugs, with the US Orphan Drug Act granting a 7-year period of market exclusivity that can protect a product even from competition from another product with the same indications.(29)

\subsection{Performance-based mechanisms}

"Performance-based risk-sharing agreements" (PBRSAs) extend VBP to make pricing depend explicitly how the therapy performs in the population, rather than how it is expected to perform. PBRSAs take many forms, including outcomes-based schemes, 
risk-sharing agreements, coverage with evidence development, access with evidence development (AED), patient access schemes, conditional licensing, and managed entry agreements.(23,30-35) The 2013 ISPOR task force report on PBRSAs discusses the design choices more fully.(30) The key features of PBRSAs are that (1) data on outcomes is collected following regulatory approval and introduction of the drug to the market, and (2) the reimbursement to the manufacturer is conditional on the data collected.(30)

Evidently, for PBRSAs to be different from a standard pricing arrangement, it must be the case that there is some uncertainty about the outcomes that the drug will generate. (Otherwise, payers could spare themselves the trouble of collecting data.) Because this uncertainty is resolved as the drug comes to market and the data is collected, it is apparent that PBRSAs "better align the rewards to the manufacturer with the value that the patients - represented by the payers - would assign to the new intervention."(p. 706) (30) It is, however, unclear what effect this improved alignment will have.

PBRSAs do not obviously create savings for payers compared to standard VBP mechanisms. For example, if the structure of the PBRSA is a money-back guarantee, the manufacturer only receives payment when the product is successful in an individual patient. Suppose that a drug is expected to be successful at creating 10 QALYs (on average) in 50\% of patients, and has no effect in the remaining $50 \%$. Then, using a standard VBP approach and a threshold of say $\$ 20,000$, the payer should be willing to pay $\$ 100,000$ per patient treated. With a PBRSA, the payer will pay for only the successful treatments, but should pay up to $\$ 200,000$ per patient. The overall cost to the payer and revenue to the manufacturer are almost unchanged, assuming that expectations are, on average, correct and that the marginal production cost is relatively small. (If expectations are systematically biased, for example because payers do not learn from experience, then PBRSAs may of course affect expenditures.)

In practice, PBRSAs appear to have had a limited impact on spending. In Italy, which has been particularly active in using risk-sharing contracts, PBRSAs have been structured so that they offer reimbursement of the insurer by the manufacturer in cases of non-responding patients. Total spending on drugs with such risk-sharing schemes was EUR3.7bn during the period 2006-12, but the total amount of reimbursement to the insurer was EUR121m, or about 3\%.(36) Given that manufacturers must have required a higher price in order to accept the risk of having to make reimbursement, $3 \%$ is an upper bound on the amount of savings generated by the risk-sharing schemes. In addition, as there are substantial costs to contracting and then enforcing PBRSAs (37), it is unclear whether risk-sharing agreements will confer much financial benefit to payers. A different approach in which additional payments were made based on exceeding some standard, rather than repayment required in case of non-response, might generate more savings.

A separate question is whether this improved alignment of rewards with social value leads to more efficient incentives to invest in innovative therapies. The decision to invest in developing a new therapy will depend on the revenues expected at that 
time. Those revenues will depend on the expected volume times the expected price. A PBRSA would not change the incentive to invest in developing the therapy unless it changed either the expected volume or the expected price. The effect of PBRSA is that it makes the price dependent on the actual outcomes, instead of the expected outcomes. If the expected outcomes of new therapies are the same, on average, as actual outcomes, then on average the price will be the same with and without a PBRSA. At the time of investing in developing a drug, the innovator must, however, rely on expectations, which are therefore the same with and without a PBRSA. This means that PBRSAs should not substantially change the set of innovations that come to market, compared to a "standard" VBP scheme in which prices are based on the expected performance of the new product.

PBRSAs may be particularly relevant as a tool to incentivize manufacturers to develop appropriate evidence on the effectiveness and safety of products. For example, a PBRSA could be designed to make the price conditional on the quality of data and the reduction in uncertainty about how optimally to use a given therapy.(38) AED schemes may similarly enable early access to an innovative product for patients who have poor alternatives, while controlling access for patients who have good alternatives.(23) AED schemes may be required when the payer or regulator faces uncertainty about safety, efficacy, or budgetary implications.(23)

PBRSAs do not appear to be a solution to the problem of funding for innovative therapies, although such agreements have often been represented as a tool to achieve "financial sustainability."(39) They are unlikely to substantially change incentives for innovation; they are unlikely to change total expenditures much, on average; and to the extent that they generate improved information about how to target and use new therapies optimally, they do so at an additional cost because of the need to collect data. However, PBRSAs do at least enable payers to feel comfortable that they are receiving good value for specific innovative therapies reimbursed, and this may be an important component to sustainability of financing.

\section{Cost-based pricing}

A different strategy to achieve sustainability is cost-based pricing. When both the cost of an innovation and its value can be observed by government, then the "best" mechanism for supporting innovation is for the government to commission a firm to develop the innovation and then to pay the firm based on its costs at the time of delivery.(40) Of course, knowledge of both cost and value is unlikely, particularly in advance of the development of the innovation, which is why incentive systems based on value observed ex post are used. In addition, basing price on cost in an innovative industry may badly skew incentives towards spending money on innovations with little value.

Despite this, costs are sometimes viewed as a relevant part of the pricing decision. For example, Jeffrey Sachs has argued that Gilead should be compensated based on its cost in developing sofosbuvir, which he estimates as at most $\$ 500 \mathrm{~m}$. He reckons that since only about $10 \%$ of drugs are brought successfully to market, Gilead 
deserves to earn a "prize" of $\$ 5 \mathrm{bn}$.(41) Being fully compensated for the risk-adjusted cost of development, he proposes, should be sufficient to induce firms to invest. This approach is reminiscent of the UK's Pharmaceutical Price Regulation Scheme, which controlled prices through a complex calculation based on a maximum rate of return on capital invested.(42) This scheme was designed to reward inputs rather than outputs.(43) In such a system, a low-value product produced at high cost may have a higher regulated price than a high-value product produced at a low cost, distorting investment choices.(44)

Various studies, often cited by industry, calculate the cost of bringing a new drug to market.(45,46) In a way, these papers subtly reinforce the idea that compensation should somehow be related to cost, at least on average, since they are often used to provide a justification for high prices. This information is, however, a two-edged sword, since if companies can argue that they need high prices because their costs of R\&D are high, payers can equally argue that revenues for drugs should not be far above the estimated average cost.

Indeed, exactly this sort of reasoning seems to underlie the set of proposed regulations in the US states that call for pharmaceutical companies to justify their prices and to provide transparency about their research costs.(47) While these proposals have not yet been turned into law, they do suggest a trend in the way that governments are thinking about how to make pharmaceuticals sustainable. The recent Senate report on how Gilead brought sobosbuvir to market, and then priced it, shows that at least parts of the US government are considering how prices relate to the cost of development.(48)

Danzon and Towse (2003) make a related argument: they claim that "Under well-designed differential pricing, prices in affluent (and, to a lesser extent, middle income countries) exceed the marginal cost of production and distribution in these countries by enough, in aggregate, to cover the joint costs of $\mathrm{R} \& \mathrm{D}$, while prices in [developing countries] cover only their marginal cost."(49) The core assumption here is that because of monopolistic competition, economic profits are driven to zero in the long run. With the proposed differential pricing, countries would bear a Ramseyefficient (i.e. deadweight loss-minimizing) share of costs. This model also implies that prices should ultimately be related to underlying costs.

For some orphan drugs, there may be a case for using the average cost of drug development as a tool in pricing negotiations.(42) The challenge is that the normal value-based pricing methodologies are inoperable for some "ultra-orphan" drugs, which are far from meeting the usual cost-effectiveness thresholds. As a result, payers are faced with the problem of deciding whether to pay for an expensive medicine, but they cannot apply their standard decision rules that are based on cost-effectiveness. A cost-based pricing rule at least creates some kind of upper bound on a reasonable price in cases in which the insurer faces an imperative to reimburse the medicine.

Generally, it is clear that cost-based pricing could create significant problems. The most important of these is that, if rewards are not related to the value of innovations, the incentives to invest in what society values the most will be undermined. The strength of our patent system, as Adam Smith noted in 1763, is its 
foundation on the principle that innovation is directed to the areas where there is the greatest willingness to pay.(50) [P. 83] If innovators were rewarded based on their costs because they invented something "good enough" to get a patent, there would be a flood of worthless inventions. While there may be special circumstances in which costs are relevant, a general cost-based system of price controls would face intractable problems of misallocating rewards.

\section{Direct non-commercial funding}

\subsection{Government-funded research}

A completely different approach to sustainable finance for innovative therapies is direct investment by government in $\mathrm{R} \& \mathrm{D}$. Most high-income countries have a substantial investment in basic R\&D through national research programs such as the US's National Institutes of Health (NIH). To an increasing extent, governments are also involved in later-stage clinical research. Government funding contributes significantly to the research program of pharmaceutical companies, with recent research finding that each $\$ 10 \mathrm{~m}$ in NIH pharmaceutical investment yielding 2.3 patents.(51) Assuming reasonable patent valuations, NIH research generates considerable private value captured by pharmaceutical companies, much greater than the NIH's expenditures; and the social value is of course even greater.(51) This seems to imply that governments spend too little on state-funded medical research, if they value both patient welfare and firm profits.

Another argument for government-funded research is that governments have a lower cost of capital and lower discount rate. Since the cost of capital is a very important aspect of the total cost of innovation, because of the long delay from early research to the time when a medicine is actually used in the market, government could have a substantial cost advantage in doing research, compared to industry.(52) To be sure, there are many other issues that come into play regarding incentives and the ability of government to manage a complex and risky discovery process. However, the advantage of government in the earliest-stage research is considerably enhanced by its lower cost of capital.

Governments also contribute to the research process through the structure of the tax system. In many countries there is special treatment of R\&D expenses in the tax code. A particularly important tool here is the orphan drug tax credit in the US, which effectively subsidizes clinical trial costs for orphan drugs. One concern commonly expressed is that taxpayers may end up "paying twice" for a medicine, once through the tax credit and again after the product is introduced to the market.(53)

\subsection{Product-development partnerships}

In some cases, other entities are supporting grant-funded innovation to the point of bringing products to approval. The most important examples of this are the "product-development partnerships".(54) The most ambitious of these is likely the Drugs for Neglected Diseases initiative (DNDi) which has a business plan to launch 
16 to 18 new treatments with a total investment of EUR650m by 2023.(55) This is roughly EUR38m per treatment, which is roughly $1.5 \%$ of the $\$ 2,550 \mathrm{~m}$ investment by commercial enterprises to develop new drugs, as estimated by diMasi and colleagues.(46) If DNDi can deliver new treatments at such a tiny fraction of the cost of "big pharma", it will create a serious challenge to the structure of our current biopharmaceutical industry.

The feasibility of a significant role for product-development partnerships is supported by the success of the meningitis vaccine project, focused on developing and scaling up production of an affordable vaccine for use mainly in Africa.(56) The total costs were relatively small for this relatively low-risk product, though much greater than EUR38m. The outcome, however was highly successful and increases the credibility of PDPs as a tool for addressing the need for new drugs and vaccines in particular circumstances.

\section{Other issues}

\subsection{Delinkage}

One of the problems that arises in pharmaceutical markets in the patent system is that high prices - which are used as a reward for innovation - reduce access to potentially life-saving drugs. This phenomenon is intrinsically linked to a free market combined with exclusivity rights granted to innovators. Innovators will maximize profits by raising price until the marginal revenue is equal to marginal cost, and this generally will require that some patients or groups of patients face a price above their willingness or ability to pay. We see this in high-income markets, in which many drugs are not covered by some insurers, as well as in low-income markets, in which prices may be too high for a large fraction of the population.(57) If a patient or insurer is willing to pay more than the marginal cost of production, but less than the price, then there are deadweight losses.

One approach to avoiding the inefficiencies caused by monopoly pricing is to separate (or "delink") the reward to the innovator from the price. One way of achieving this, as described above, is for society to fund R\&D directly, and to allow competitive production of the resulting medicines. A second approach is to establish a reward or prize for developing a new medicine, which is then competitively produced. Delinkage has attracted considerable attention as a solution for antibiotics, which are challenged by the fact that commercial profits for these drugs do not appear to match the option value created by having antibiotics in reserve.(58) A key challenge for delinkage mechanisms is to determine how large this reward or prize should be. The obvious strategy is to make the reward dependent on the therapeutic value of the medicine.

Senator Bernie Sanders introduced a bill into the US Congress to reform the entire pharmaceutical research system on the basis of delinkage.(59) A more modest effort along these lines is the Health Impact Fund proposal, under which the reward would be based on the health impact of the medicine in use.(60) The proposal is for a 
large fund that would pay out a fixed amount annually, with the amount to be divided between all registered medicines annually. Registration would be optional, so that the reward rate would be self-regulating. Each registered product would have 10 years in the reward pool. A core part of the proposal is that it would allow products that are therapeutically important but not commercially valuable to be rewarded appropriately - for example, drugs for currently neglected diseases could generate substantial revenues.

The approach faces two key challenges. First, measurement of the impact of a medicine is necessarily imperfect: how much imperfection can be tolerated in a system in which payments are based on assessed impact? This is, of course, a central question in many PBRSAs, as discussed above. Second, the fund would require collaboration between governments to financially support a substantial ongoing expense, estimated to be roughly $\$ 6$ bn per year, outside of their control.

The Health Impact Fund would have the potential to increase the overall costeffectiveness of medicines, because it could allow for increased volumes without additional reimbursement. This property arises because the price of registered medicines is equal to their cost of production, thus allowing greater volume. Assuming that the total profit of the manufacturer is the same, by eliminating the deadweight loss attributable to high prices, total surplus increases. (Raising money to pay for rewards, of course, could create its own inefficiencies.) However, in countries with comprehensive, universal insurance for pharmaceuticals, its effects would be small.

\subsection{Exclusivity}

While patents have become increasingly standardized through World Trade Organization agreements, the duration of exclusivity enjoyed by an innovative drug varies substantially within and across countries.(61) Differences of interpretation in patent law, as well as other exclusivity measures, are very important, and this results in different effective exclusivity periods.(62) Tools include: patent term extensions in response to the regulatory delays; patent term extensions as a reward for pediatric trials; orphan drug market exclusivity; data exclusivity; and linkage. Some countries, led by India, have moved aggressively to restrict the set of inventions that are eligible for protection.(63) While driving down prices through, for example, compulsory licensing can enhance access and increase consumer surplus, there is some evidence that it is possible for countries to act too aggressively.(64)

Within the context of a fixed total budget, one can see that various permutations of which drug gets what length of exclusivity mainly have the effect of rearranging how the money is distributed. That is, if the exclusivity period is lengthened for some drugs, it simply tightens budgetary constraints, leading either to lower prices or to fewer approved products. If the permutations do not result in more effective targeting of innovation expenditure, then they do not create any benefit, even for industry.

The average length of exclusivity may however be a potent tool for increasing the value proposition of new therapies. The reason is that companies and investors 
tend to have a higher discount rate than governments. The same is true for the cost of borrowing: corporate bond yields are higher than government bond yields for most high-income countries. Estimates of the cost of equity capital range between $9 \%$ and $14 \%$ for pharmaceutical, biotech, and devices industries during the period 2001 2008.(65) During the same period, US government 10-year bond rates averaged around $5 \%$, indicating a substantial discrepancy between the private and public costs of capital.

For the sake of simplicity, assume that governments have a discount rate of $0 \%$, and companies have an effective discount rate of $10 \%$. If a company makes profits of $\$ 1 \mathrm{~m}$ per year given a mark-up of $\$ 1$ per pill, the net present value to the company is $\$ 6.2 \mathrm{~m}$ over a ten-year exclusivity period. If the government grants a 5 -year exclusivity period and allows a mark-up of $\$ 2$ per pill, its cost is the same; but the net present value to the company is now $\$ 7.8 \mathrm{~m}$, about $25 \%$ higher. The key is that if there is a difference between the cost of capital to the pharmaceutical industry and the cost of capital to the government, front-loading the payment to pharmaceutical manufacturers substantially increases incentives to develop new drugs at little cost to the government.

Ironically, pharmaceutical manufacturers have been pushing for longer exclusivity. $(62,66)$ This strategy only makes sense in a ceteris paribus world in which budgets are not fixed and prices do not respond to exclusivity periods. Possibly industry is correct in assuming that prices are unresponsive to the average exclusivity period; however, even if prices are unresponsive, it seems likely that the set of covered drugs is responsive. As exclusivity periods increase, the insurer's budget becomes more constrained, and fewer drugs are covered. If the budget is fixed, longer exclusivity periods caused by changes to patents cannot increase total spending: they only shift the revenues across products. Given this set of observations, and assuming a wedge between the public and private cost of capital, the effort to extend patent terms may undermine the financial sustainability of our systems of medical innovation without benefiting industry.

\section{Conclusions}

The complexity of medical innovation, with its range of different actors, presents a supremely challenging set of problems for sustainable financing. Fundamentally, we lack information on how much the world, or any country, should spend on supporting medical innovation; and we don't know how to allocate a given budget across different potential or existing therapies. The result is a continuing competition between different ideas and institutional structures. As evidence mounts on the effectiveness of one or another, support shifts along with the shares of the total funding stream. In this context, it seems that the best hope for "sustainable" financing for innovative therapies is a continuing evolution of the structure of how we pay for new therapies. 
Acknowledgments. The comments of the editor and two referees, Chris McCabe and Brita Pekarsky, considerably improved the paper. The author takes responsibility for remaining errors.

\section{Compliance with Ethical Standards.}

Funding. The author acknowledges support from a Canadian Institutes of Health Research Emerging Team Grant on Developing Effective Policies for Managing Technologies for Rare Diseases and the European Research Council under the European Union's Seventh Framework Programme (FP/2007-2013) / ERC Grant Agreement no. 339239.

Conflicts of interest. The author has been an expert witness in litigation for Apotex, Teva, Sandoz, TearLab, and Cobalt and has received honoraria from the OECD, the Competition Bureau and the government of Ecuador.

\section{References}

1. Pekarsky BAK. The New Drug Reimbursement Game. Heidelberg: Springer International Publishing; 2015.

2. Hailey D. Development of the International Network of Agencies for Health Technology Assessment. Int J Technol Assess Health Care [Internet]. 2009;25 Suppl 1:24-7. Available from: http://www.ncbi.nlm.nih.gov/pubmed/19500434

3. Jönsson B. Relative effectiveness and the European pharmaceutical market. Eur J Heal Econ. 2011;12(2):97-102.

4. Persson U, Jönsson B. The End of the International Reference Pricing System? Appl Health Econ Health Policy [Internet]. 2015;1-8. Available from: http://link.springer.com/10.1007/s40258-015-0182-5

5. Rémuzat C, Urbinati D, Mzoughi O, El Hammi E, Belgaied W, Toumi M. Overview of external reference pricing systems in Europe. J Mark Access Heal Policy. 2015;3.

6. Maguire PT, Gibson E. The Cancer Drugs Fund and Patient Acces Schemes within the UK: Increased Access to Oncology Medicines or Reduced Value For Money? Value Heal. Elsevier; 2015;18(7):A484.

7. Picavet E, Dooms M, Cassiman D, Simoens S. Orphan drugs for rare diseases: Grounds for special status. Drug Dev Res. 2012;73(3):115-9.

8. Sussex J, Towse A, Devlin N. Operationalizing value-based pricing of medicines: A taxonomy of approaches. Pharmacoeconomics. 2013;31(1):1-10.

9. Neumann PJ, Cohen JT, Weinstein MC. Updating Cost-Effectiveness - The Curious Resilience of the \$50,000-per-QALY Threshold. N Engl J Med [Internet]. 2014;371(9):796-7. Available from: 
http://www.ncbi.nlm.nih.gov/pubmed/25162885

10. Ramsey S, Willke R, Glick H, Reed SD, Federico A, Jonsson B, et al. CostEffectiveness Analysis Alongside Clinical Trials II - An ISPOR Good Research Practives Task Force Report. Value Heal. 2015;18:161-72.

11. Brazier JE, Yang Y, Tsuchiya A, Rowen DL. A review of studies mapping (or cross walking) non-preference based measures of health to generic preferencebased measures. Eur J Heal Econ. 2010;11(2):215-25.

12. Chan KKW, Willan AR, Gupta M, Pullenayegum E. Underestimation of Uncertainties in Health Utilities Derived from Mapping Algorithms Involving Health-Related Quality-of-Life Measures: Statistical Explanations and Potential Remedies. Med Decis Mak [Internet]. 2014;34(7):863-72. Available from: http://mdm.sagepub.com/cgi/doi/10.1177/0272989X13517750

13. Larson EB, Tachibana C, Thompson E, Coronado GD, DeBar L, Dember LM, et al. Trials without tribulations: Minimizing the burden of pragmatic research on healthcare systems. Healthcare [Internet]. Elsevier; 2015;1-4. Available from: http://dx.doi.org/10.1016/j.hjdsi.2015.07.005

14. Kalkman S, Van Thiel GJMW, Grobbee DE, Van Delden JJM. Pragmatic randomized trials in drug development pose new ethical questions: a systematic review. Drug Discov Today [Internet]. Elsevier Ltd; 2015;20(7):856-62. Available from: http://dx.doi.org/10.1016/j.drudis.2015.03.005

15. Appleby J, Devlin N, Parkin D, Buxton M, Chalkidou K. Searching for cost effectiveness thresholds in the NHS. Health Policy (New York). 2009;91(3):239-45.

16. Claxton K, Briggs A, Buxton MJ, Culyer AJ, McCabe C, Walker S, et al. Value based pricing for NHS drugs: an opportunity not to be missed? BMJ Br Med J. 2008;336(7638):251-4.

17. JOHN LONDON A. How Should We Model Rare Disease Allocation Decisions? Hastings Cent Rep [Internet]. 2012;42(1):3-3. Available from: http://doi.wiley.com/10.1002/hast.3

18. Claxton K, Martin S, Soares M, Rice N, Spackman E, Hinde S, et al. Methods for the estimation of the National Institute for Health and care excellence costeffectiveness threshold. Health Technol Assess (Rockv). 2015;19(14):1-503.

19. Jamison DT, Summers LH, Alleyne G, Arrow KJ, Berkley S, Binagwaho A, et al. Global health 2035: A world converging within a generation. Lancet [Internet]. Elsevier Ltd; 2013;382(9908):1898-955. Available from: http:/ /dx.doi.org/10.1016/S0140-6736(13)62105-4

20. Marseille E, Larson B, Kazi DS, Kahn JG, Rosen S. Thresholds for the cost effectiveness of interventions: alternative approaches. Bull World Health Organ. 2015;93(October 2014):118-24.

21. Ochalek J, Lomas J, Claxton K. Cost Per DALY Averted Thresholds for Lowand Middle-Income Countries: Evidence from Cross-Country Data. CHE 
Research Paper 122. 2015.

22. Woods B, Revill P, Sculpher M, Claxton K. Country-Level Cost-Effectiveness Thresholds: Initial Estimates and the Need for Further Research. 2015.

23. Stafinski T, McCabe CJ, Menon D. Funding the Unfundable. Pharmacoeconomics. 2010;28(2):113-42.

24. Towse A, Garrison LP. Can't Get No Satisfaction? Will Pay for Performance Help? Pharmacoeconomics. 2010;28(2):93-102.

25. Niezen MGH, Bont A De, Busschbach JJ V, Cohen JP, Stolk EA. Finding legitimacy for the role of budget impact in drug reimbursement decisions. 2009;1:49-55.

26. Loury G. Market Structure and Innovation. Q J Econ. 1979;93(3):395-410.

27. Dimasi JA, Paquette C. The Economics of Follow-on Drug Research and Development. Pharmacoeconomics. 2004;22 Suppl. :1-14.

28. Hollis A. Comment on "The Economics of Follow-on Drug Research and Development”. Pharmacoeconomics. 2005;23(12):1187-92.

29. Fagnan DE, Gromatzky AA, Stein RM, Fernandez JM, Lo AW. Financing drug discovery for orphan diseases. Drug Discov Today [Internet]. Elsevier Ltd; 2014;19(5):533-8. Available from: http://dx.doi.org/10.1016/j.drudis.2013.11.009

30. Garrison LP, Towse A, Briggs A, De Pouvourville G, Grueger J, Mohr PE, et al. Performance-based risk-sharing arrangements - Good practices for design, implementation, and evaluation: Report of the ISPOR good practices for performance-based risk-sharing arrangements task force. Value Heal [nternet]. Elsevier; 2013;16(5):703-19. Available from: http://dx.doi.org/10.1016/j.jval.2013.04.011

31. Carlson JJ, Sullivan SD, Garrison LP, Neumann PJ, Veenstra DL. Linking payment to health outcomes: A taxonomy and examination of performancebased reimbursement schemes between healthcare payers and manufacturers. Health Policy (New York) [Internet]. Elsevier Ireland Ltd; 2010;96(3):179-90. Available from: http://dx.doi.org/10.1016/j.healthpol.2010.02.005

32. De Pouvourville G. Risk-sharing agreements for innovative drugs: A new solution to old problems? Eur J Heal Econ. 2006;7(3):155-7.

33. Hutton J, Trueman P, Henshall C. Coverage with evidence development: an examination of conceptual and policy issues. Int J Technol Assess Health Care. 2007;23(4):425-32.

34. Garber AM, McClellan MB. Satisfaction Guaranteed — "Payment by Results" for Biologic Agents. N Engl J Med. 2007;16(357):1575-7.

35. Cook JP, Vernon JA, Manning R. Risk-Sharing Agreements. Pharmacoeconomics. 2008;26(7):551-6. 
36. Navarria A, Drago V, Gozzo L, Longo L, Mansueto S, Pignataro G, et al. Do the current performance-based schemes in Italy really work? "Success fee": A novel measure for cost-containment of drug expenditure. Value Heal [Internet]. Elsevier; 2015;18(1):131-6. Available from: http://dx.doi.org/10.1016/j.jval.2014.09.007

37. Edlin R, Hall P, Wallner K, McCabe C. Sharing risk between payer and provider by leasing health technologies: An affordable and effective reimbursement strategy for innovative technologies? Value Heal [Internet]. Elsevier; 2014;17(4):438-44. Available from: http://dx.doi.org/10.1016/j.jval.2014.01.010

38. Claxton K. Oft, Vbp: Qed? Health Econ. Wiley Online Library; 2007;16(6):545-58.

39. Kanavos P, Mills M. Options for the Sustainable Financing of Innovative Therapies. 2015.

40. Gallini N, Scotchmer S. Intellectual property: when is it the best incentive system? Innovation Policy and the Economy, Volume 2. MIT Press; 2002. p. $51-78$.

41. Sachs J. Rational Drug Pricing. Huffington Post [Internet]. 2015; Available from: http://www.huffingtonpost.com/jeffrey-sachs/rational-drugpricing_b_8188790.html

42. Fellows GK, Hollis A. Funding innovation for treatment for rare diseases: adopting a cost-based yardstick approach. Orphanet J Rare Dis [Internet]. Orphanet Journal of Rare Diseases; 2013;8(1):180. Available from: http://www.pubmedcentral.nih.gov/articlerender.fcgi?artid=3832748\&tool $=p$ mcentrez\&rendertype $=$ abstract

43. Office of Fair Trading. Pharmaceutical Price Regulation Scheme, Annexe H [Internet]. $2007 . \quad$ Available from: http://webarchive.nationalarchives.gov.uk/20140402142426/http://www.oft. gov.uk/shared_oft/reports/comp_policy/oft885.pdf

44. Averch H, Johnson LL. Behavior of the firm under regulatory constraint. Am Econ Rev. JSTOR; 1962;52(5):1052-69.

45. DiMasi JA, Hansen RW, Grabowski HG. The price of innovation: New estimates of drug development costs. J Health Econ. 2003;22(2):151-85.

46. DiMasi JA, Grabowski HG, Hansen RW. INNOVATION IN THE PHARMACEUTICAL INDUSTRY: NEW ESTIMATES OF R\&amp;D COSTS. J Health Econ [Internet]. Elsevier B.V.; 2016; Available from: http://linkinghub.elsevier.com/retrieve/pii/S0167629616000291

47. Chiu S. Pharmaceutical Cost Transparency Act of 2016. California Assembly; 2016.

48. Wyden R, Grassley C. The Price of Sovaldi and Its Impact on the U.S. Health Care System [Internet]. 2015. Available from: 
http://www.finance.senate.gov/newsroom/ranking/release/?id=3f693c730fc2-4a4c-ba92-562723ba5255

49. Danzon PM, Towse A. Differential Pricing for Pharmaceuticals: Reconciling Access, R\&D and Patents. Int J Health Care Finance Econ. 2003;3(3):183-205.

50. Smith A. Lectures on Jurisprudence, ed. by RL Meek, DD Raphael and PG Stein. Glasgow Ed. Vol V. Indianapolis: Liberty Fund; 1982.

51. Azoulay P, Zivin JSG, Li D, Sampat BN. Public R\&D Investments and Private-sector Patenting: Evidence from NIH Funding Rules. Natl Bur Econ Res Work Pap Ser [Internet]. 2015;No. 20889. Available from: http://www.nber.org/papers/w20889\nhttp://www.nber.org/papers/w20889 .pdf

52. Hemel DJ, Ouellette LL. Beyond the Patents - Prizes Debate. Tex Law Rev. 2013;92:303-82.

53. Seoane-Vazquez E, Rodriguez-Monguio R, Szeinbach SL, Visaria J. Incentives for orphan drug research and development in the United States. Orphanet J Rare Dis [Internet]. 2008;3:33. Available from: http://www.pubmedcentral.nih.gov/articlerender.fcgi?artid $=2631478 \&$ tool $=p$ mcentrez\&rendertype $=$ abstract

54. Moran M, Guzman J, Ropars AL, Illmer A. The role of Product Development Partnerships in research and development for neglected diseases. Int Health. 2010;2(2):114-22.

55. DNDi. Business Plan 2015-2023 [Internet]. 2015. Available from: www.dndi.org

56. Bishai DM, Champion C, Steele ME, Thompson L. Product development partnerships hit their stride: Lessons from developing a meningitis vaccine for Africa. Health Aff. 2011;30(6):1058-64.

57. Flynn S, Hollis A, Palmedo M. An economic justification for open access to essential medicine patents in developing countries. J Law Med Ethics [Internet]. 2009;37(2):184-208. Available from: http://www.ncbi.nlm.nih.gov/pubmed/19493066

58. Servick K. The drug push. Science [Internet]. 2015;348(6237):850-3. Available from: http://www.ncbi.nlm.nih.gov/pubmed/25999488

59. Sanders B. Medical Innovation Prize Fund Act [Internet]. 2007 p. 1-23. Available from: https://www.govtrack.us/congress/bills/113/s627

60. Banerjee A, Hollis A, Pogge T. The Health Impact Fund: incentives for improving access to medicines. Lancet [Internet]. 2010;375(9709):166-9. Available

from: http:/ /www.thelancet.com/article/S0140673609612964/fulltext

61. Wang B, Liu J, Kesselheim AS. Variations in time of market exclusivity among top-selling prescription drugs in the United States. JAMA Intern Med [Internet]. 
2015;175(4):635-7.

Available

from:

http:/ /archinte.jamanetwork.com/article.aspx?articleID=2109854

62. Liu M, La Croix S. A cross-country index of intellectual property rights in pharmaceutical inventions. Res Policy [Internet]. Elsevier B.V.; 2015;44(1):20616. Available from: http://dx.doi.org/10.1016/j.respol.2014.07.004

63. Liu J. Compulsory Licensing and Anti-Evergreening: Interpreting the TRIPS Flexibilities in Sections 84 and 3 (d) of the Indian Patents Act. Harv Int'l LJ. HeinOnline; 2015;56:207.

64. Chatterjee C, Kubo K, Pingali V. The consumer welfare implications of governmental policies and firm strategy in markets for medicines. J Health Econ. Elsevier B.V.; 2015;44:255-73.

65. Harrington SE. Cost of capital for pharmaceutical, biotechnology, and medical device firms. In: Danzon PM, Nicholson S, editors. The Oxford Handbook of the Economics of the Biopharmaceutical Industry2012. Oxford University Press; 2009.

66. Gleeson DH, Neuwelt P, Monasterio E, Lopert R. How the transnational pharmaceutical industry pursues its interests through international trade and investment agreements: a case study of the Trans Pacific Partnership. Handb Res Transnatl Corp Alice Jong Rom Tomasic (eds), Edward Elgar Publ Ltd(forthcoming). 2015. 